\title{
Colorimetric capnography: a misnomer worth correcting
}

\author{
Robert Canelli ${ }^{1,2} \cdot$ Rafael Ortega $^{1}$ \\ Received: 22 January 2021 / Accepted: 27 January 2021 / Published online: 9 February 2021 \\ (c) The Author(s), under exclusive licence to Springer Nature B.V. part of Springer Nature 2021
}

The treatment of Coronavirus disease 2019 (Covid-19) includes endotracheal intubation in patients with respiratory failure. Capnography, defined as the graphical display of exhaled carbon dioxide concentration over time, is best suited to corroborate endotracheal intubation. However, a time-limited colorimetric test, which uses a pH-sensitive chemical indicator that changes color when carbon dioxide is detected, can also be used. The term "colorimetric capnography" is often used to describe this chemical detection of carbon dioxide [1-3]. Considering that the chemical indicator color change only provides qualitative information without a continuous waveform, the terms "colorimetric capnography" and "colorimetric capnometry" should be discouraged as they undermine the intended meaning of "capnography." Instead, the terms "carbon dioxide colorimetry", "colorimetric carbon dioxide detection", and "chemical colorimetric analysis" seem more appropriate.
Robert Canelli

Robert.canelli@bmc.org

1 Department of Anesthesiology, Boston Medical Center, Boston University School of Medicine, Boston, MA, USA

2 Boston University School of Medicine, 750 Albany Street, Suite 2R, Boston, MA 02118, USA
Author contributions $\mathrm{RC}$ and $\mathrm{RO}$ developed the idea for this letter and researched the topic together. Authors consent to participate and for publication.

Funding This study was performed without internal or external funding.

\section{Compliance with ethical standards}

Conflict of interest Authors report no relevant conflicts of interest.

\section{References}

1. Meyer P, Henry M, Maury E, Baudel JL, Guidet B, Offenstadt G. Colorimetric capnography to ensure correct nasogastric tube position. J Crit Care. 2009;24(2):231-5. https://doi.org/10.1016/j. jcrc.2008.06.003.

2. Naik ND, Hernandez MC, Anderson JR, Ross EK, Zielinski MD, Aho JM. Needle decompression of tension pneumothorax with colorimetric capnography. Chest. 2017;152(5):1015-20. https:// doi.org/10.1016/j.chest.2017.04.179.

3. Zietlow J, Hernandez M, Bestland A, Musa J, Ferrara M, Berns K, Anderson J, Zielinski M, Aho J. Decompression of tension pneumothorax in a trauma patient -first use of a novel decompression colorimetric capnography device in human patient. Gen Thorac Cardiovasc Surg. 2020. https://doi.org/10.1007/s11748-020-01471-7.

Publisher's Note Springer Nature remains neutral with regard to jurisdictional claims in published maps and institutional affiliations. 